\title{
Corrections
}

\section{Correction: Javadi et al., “Oscillatory Reinstatement Enhances Declarative Memory”}

In the article "Oscillatory Reinstatement Enhances Declarative Memory" by Amir-Homayoun Javadi, James C. Glen, Sara Halkiopoulos, Mei Schulz, and Hugo J. Spiers, which appeared on pages 9939-9944 of the October 11, 2017 issue, the authors regret a typo in Figure 1. The error in Figure $1 \mathrm{a}$ had the duration indicated as $6 \mathrm{~h}$, but should be instead listed as $1.5 \mathrm{~h}$, as also stated in the Procedure subsection on page 9940. This correction does not affect the conclusions of the paper. Figure 1 has been corrected in the online PDF version and is displayed below.

a

\begin{tabular}{|c|c|cc|c|}
\cline { 4 - 5 } \multicolumn{2}{c|}{ Task } & & \multicolumn{2}{c|}{ Task } \\
\hline \multicolumn{2}{|c|}{ tACS } & & \multicolumn{2}{c|}{ tACS } \\
\hline $5^{\prime}$ & $10^{\prime}$ & 1.5 hours & $5^{\prime}$ & $10^{\prime}$ \\
\hline \multicolumn{2}{|c|}{ Encoding Phase } & Retention Interval & \multicolumn{3}{c|}{ Recognition Phase } \\
\hline
\end{tabular}

b

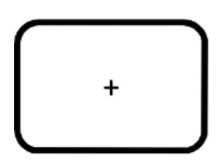

fixation cross

$1 \mathrm{~s}$

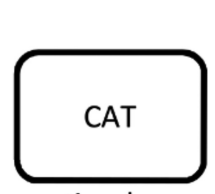

stimulus

$0.6 \mathrm{~s}$

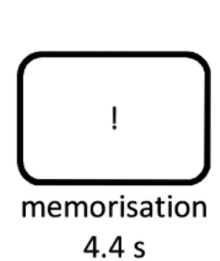

c

d

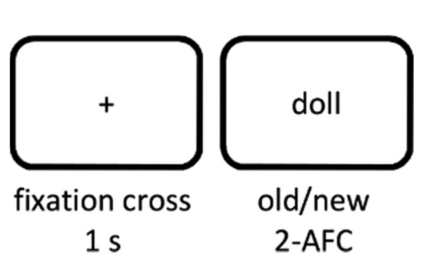

Encoding

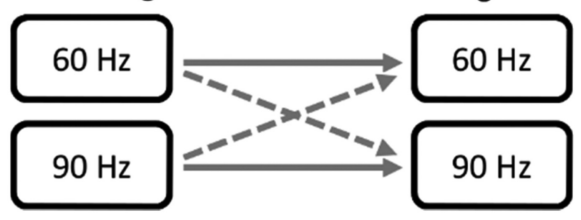

e

\section{$60 \mathrm{~Hz}$} 30 s

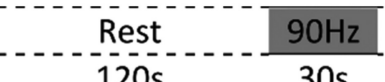

$30 \mathrm{~s}$

\section{Rest} $120 \mathrm{~s}$ ... 9 repetitions ...

\section{$60 \mathrm{~Hz}$}

$30 \mathrm{~s}$
$60 \mathrm{~Hz}$

$30 \mathrm{~s}$

Figure 1.

\section{Correction: Anderson et al., "Visual Population Receptive Fields in People with Schizophrenia Have Reduced Inhibitory Surrounds"}

In this article "Visual Population Receptive Fields in People with Schizophrenia Have Reduced Inhibitory Surrounds" by Elaine J. Anderson, Marc S. Tibber, D. Sam Schwarzkopf, Sukhwinder S. Shergill, Emilio Fernandez-Egea, Geraint Rees, and Steven C. Dakin, which appeared on pages 1546-1556 of the February 8, 2017 issue, the authors regret an error in Figure 2, where the labels at the bottom of the two columns have been incorrectly switched. The correct labels are shown in the figure below and corrected on the online PDF version. 


\section{A Polar Angle Map}

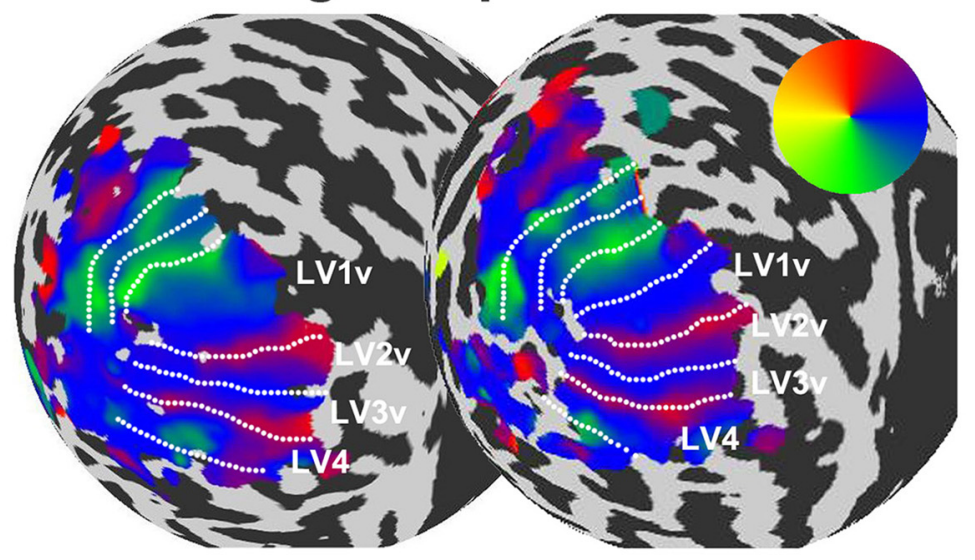

B Eccentricity Map

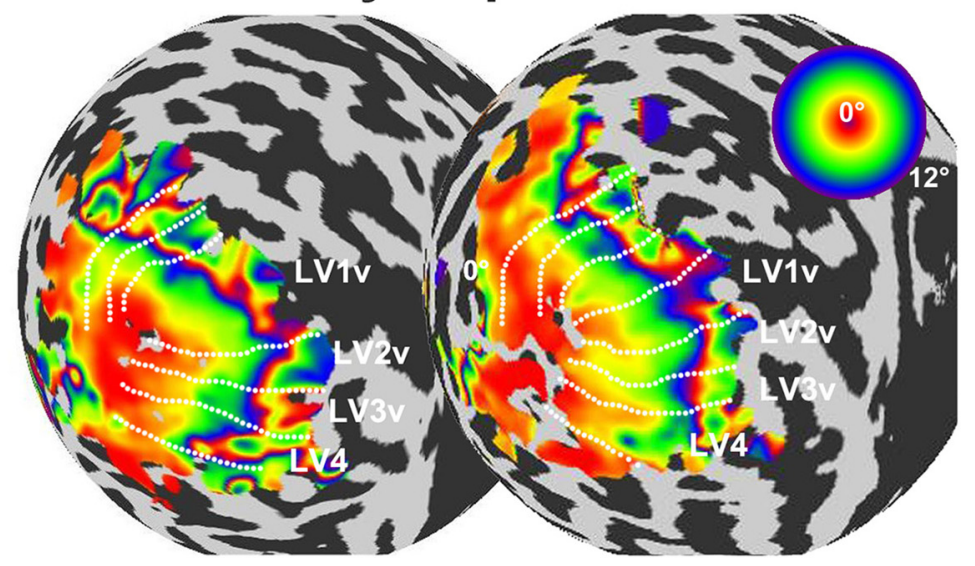

c Prf Size Map

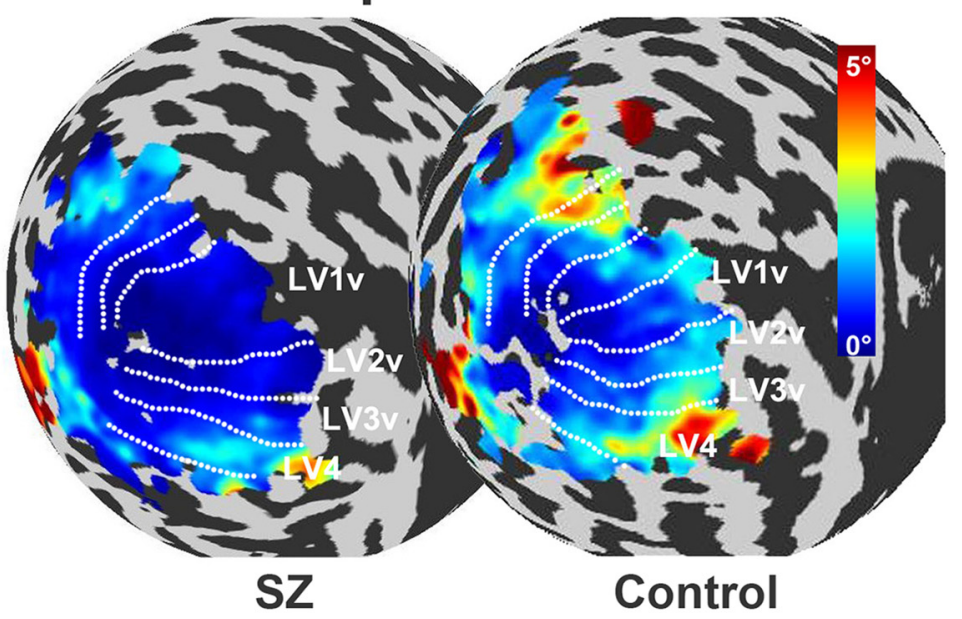

Figure 2. 